\title{
AN ANALYSIS ON THE RESEARCH ORIENTATIONS IN HEALTHCARE SIMULATION MODELING
}

\author{
Junqiao Chen \\ David Chun \\ Evolent Health \\ 800 N Glebe Rd, Arlington, Virginia, USA \\ \{qchen,dchun\}@evolenthealth.com
}

\author{
Mónica Duarte Oliveira \\ CEG-IST, Instituto Superior Técnico, \\ Universidade de Lisboa \\ Av. Rovisco Pais, 1049-001 Lisboa, Portugal \\ monica.oliveira@tecnico.ulisboa.pt
}

\author{
Alexandra Fernandes \\ Instituto Universitário de Lisboa (ISCTE-IUL) \\ Business Research Unit (BRU-IUL) \\ Av. das Forças Armadas 1649-026, Lisboa, Portugal \\ alexandra.fernandes@iscte-iul.pt
}

\begin{abstract}
Research orientation is about for whom and by whom the research is conceptualized and conducted. A clear understanding of this often-overlooked concept is crucial for the healthcare modeling community, which is searching for better stakeholder engagement, value demonstration and quality assessment. To review and categorize this concept for modelers and evaluators, we used the Framework Method to examine 35 purposively sampled studies of agent-based and discrete-event simulation modeling in healthcare operation and policy. Four research orientations emerged in the sampled studies, ranging from academic, unilateral passive stakeholder, unilateral active stakeholder, and multilateral stakeholders. From one orientation to the next, studies engage more stakeholders in more research steps and entail distinct requirements for quality assessment. Our analysis highlights the complexity of healthcare for which the best approach to engage stakeholders, demonstrate value and assess quality depends upon the research orientation.
\end{abstract}

Keywords: simulation and modeling, framework analysis, research orientation, pluralism, healthcare.

\section{INTRODUCTION}

Research orientation is about for whom and by whom the research is conceptualized and conducted (Cornwall and Jewkes 1995). Research orientation provides the fundamental context for the mode of knowledge production. While research orientation has been examined in some disciplines (Nature editors 2018), it has been largely overlooked in the healthcare modeling community, posing challenges on how to demonstrate the value and assess the quality of health simulation studies.

The diversification of research orientations, from academic only to a variety of audience and participants, has stimulated dramatic changes in the mode of knowledge production. By contrast with the traditional knowledge generated within a disciplinary context, the new mode of knowledge is created in a broader, transdisciplinary social and economic context. It is carried out in a context of application, under continuous negotiation of various stakeholders, and shaped by a more diverse set of intellectual and social demands. Thus it is more socially accountable and reflexive. It includes a wider and heterogeneous set of practitioners SpringSim-MSM, 2019 April 29 - May 2, Tucson, AZ, USA; C2019 Society for Modeling \& Simulation International (SCS) 
organized in a heterarchical way, collaborating on a problem defined in a specific and localized context (Gibbons, et al. 1994).

So far, however, the healthcare modeling community has given little attention to research orientation. When scholars discuss new paradigms of healthcare simulation modeling, the focus has largely been technological (Siebers, et al. 2010) (S. C. Brailsford 2014). Typically, healthcare simulation modeling is still an ivory tower activity, as researchers working in the "back-office" mostly develop a precise model (Robinson, et al. 2014), and then look for an opportunity to implement it. In this mode, it is not surprising to find that the implementation rate has been "depressingly low" (Brailsford, et al. 2009). Such a depressing reality has motivated some to survey why stakeholder engagement is low in healthcare simulation (Jahangirian, et al. 2015). Others have argued that, because of the wicked nature of healthcare problems, "implementation cannot be used to measure success" (Eldabi 2009). We argue that without a clearer understanding of research orientation, these discussions cannot go very far. This is because different research orientations require different levels of stakeholder engagements and different ways to demonstrate the value of research.

A better understanding of research orientation can also help literature reviewers to assess healthcare simulation models (Fone, et al. 2003). For example, Chen (2018) has recently conducted a systematic review on agent-based modeling in healthcare operations. During the review process, he found it inappropriate to only use one checklist to appraise all the retrieved studies. This is in contrast to a "typical" systematic review on randomized controlled trials of intervention, in which one standard tool is used to assess all studies (Higgins and Green 2011). The research context of a clinical trial is usually narrower and well-defined, while healthcare simulation studies answer more types of managerial and policy questions and embrace a much more diverse group of audience and participants. Consequently, there is a need to assess a study from the angle of the people to whom the study is oriented (Ofir, et al. 2016). In fact, this analysis is motivated by that experience of frustration caused by a lack of knowledge of research orientation.

As far as we know, this is the first discussion on research orientation in the context of healthcare simulation modeling. It is timely in light of the increasing pluralistic landscape in healthcare systems and of the recognition that more simulation studies could inform managerial and policy action. By analyzing literature to identify and categorize research orientations, we hope in this study to provide methodological clarification for modelers to search for new modes of model development, and for evaluators to adopt appropriate criteria to appraise these models. While modelers and evaluators are the main audience for this study, we hope it is also informative for other stakeholders (e.g., managers, clinicians) about their roles in simulation modeling.

\section{METHODS}

We propose using the Framework Method to analyze 35 studies. The Framework Method is a thematic analytic approach for textual qualitative data (Gale, et al. 2013), and these 35 studies were treated essentially as a qualitative data set. Thirty-one of these studies were the included studies from the abovementioned systematic review developed by Chen (2018). Adopting a hermeneutic approach (Boell and CecezKecmanovic 2014), another four highly-relevant studies were iteratively included in this analysis because they could add to our understanding of the topic. After these, theme saturation was reached, which means a satisfactory sample was obtained and there was no need to analyze more studies. The full list of studies can be obtained by contacting the first author.

This two-step searching approach attempted to strike a balance between being "systematic" (predetermined and exhaustive), "hermeneutic" (iterative and judiciously selective) (Greenhalgh, Thorne and Malterud 2018) and pragmatic, given the voluminous amount of literature in this topic (Brailsford, et al. 2009). Together, the 35 studies provided a purposive sample for the framework analysis, a standard practice in qualitative research to maximize diversity in a sample (Barbour 2008).

The details about the systematic review that originated the 31 studies is described in Chen (2018). Briefly, the author reviewed the application of agent-based simulation modeling in health operations. A study would 
be included if interactive patient agents were modelled, and would be excluded if there were none or only "dummy" patient agents. No restriction on publication year, type or language was applied. A versatile interdisciplinary search strategy was developed to account for materials not published in traditional journals. Over 2000 citations were identified, and 31 studies met the inclusion criteria. Eleven studies are about service efficiency, nine about nosocomial infection, four on care coordination, and the rest are on hospital layout design, patient choice, and payment model.

Departing from those 31 studies, a hermeneutic approach was followed to explore broader simulation techniques, such as discrete-event simulation, more modes of knowledge production, such as "communitybased participatory research" and "action research" (Minkler and Wallerstein 2008), and broader topic areas. Among a large amount of studies, four of them were added to the sample because they add to our understanding of research orientation. Two of them agent-based models on diabetic eye exam and cesarean delivery, and the other two are discrete-event simulations on primary care and emergency room operation, respectively.

The Framework Method was selected to analyze those studies as it is widely used in qualitative health research and its defining characteristics is a matrix output, which provides a holistic, descriptive overview of a large data set. It is a particularly appropriate approach for categorizing and organizing what may seem like unwieldy qualitative data (Gale, et al. 2013). We started by drafting a working framework based on a previous study on the research orientations in university departments (Hakala and Ylijoki 2001). This framework was constantly revised as we tried to organize more studies into it. When all research orientations fully emerged and no revision was needed for the matrix, we believed saturation was reached and there was no need to search and analyze additional studies.

The final matrix generated by applying the Framework Method to the 35 simulation modelling in health operations' studies contains 7 columns. "Orientation" describes to whom the research is oriented. "Who asks the question" describes who gets to identify the problem to solve or frame the research project. "Model developers" describes who gets to develop and validate the conceptual and computational models. "Model Users" describes who run the computer program of the model. "Knowledge Users" describes who consume the knowledge generated from the model. "Motives" describes the motivation behind conducting a research. The last column describes the unique dimensions for critically critical appraising studies within each research orientation group. Across research orientations, we expect basic scientific rigor. Thus this last column only focuses on the extra criteria that are specifically relevant to the feature of a research orientation. As elaborated in the next session, these criteria were obtained from examining extensive literature in evidence-based medicine, operation research, software engineering and research evaluation.

Because this is a qualitative analysis at its core, a frequency distribution of studies in each category would be misleading (Gale, et al. 2013) and therefore is not presented. The intent is to explore the diversity of research orientation, not the popularity.

The Results section will first present a categorization of research orientations. Each category's features is discussed, and two example studies in each category are briefly described and appraised.

\section{RESULTS}

Four typical research orientations emerged from healthcare simulation studies, as listed in Table 1.

\subsection{The Orientation to Academic}

The academic (research) orientation has as its reference point to the scientific community, which is the main audience to whom researchers want to address their results. This orientation reflects traditional academic values and norms, such as academic freedom and a curiosity-driven choice of research topics. The nature of knowledge is theoretical and researchers' main motive in their work is to achieve recognition within the scientific community (Hakala and Ylijoki 2001). Besides methodological rigor, the critical 
appraisal of these studies should also pay attention to originality (Greenhalgh 2014). In fact, because academic research funders are generally looking for innovative approaches, a low percentage of healthcare simulation studies in the academic literature employed common modeling methods, as evident in a review of 342 articles that $53 \%$ of the articles had a primary modeling method that was not observed in more than two articles (Brailsford, et al. 2009). The quality items in the appraisal will depend more on the method employed.

Table 1: Research Orientations in Healthcare Simulation Studies.

\begin{tabular}{|c|c|c|c|c|c|c|}
\hline Orientation & $\begin{array}{l}\text { Who ask } \\
\text { the } \\
\text { question }\end{array}$ & $\begin{array}{l}\text { Model } \\
\text { Developer } \\
\text { s }\end{array}$ & Model Users & $\begin{array}{l}\text { Knowledge } \\
\text { Users }\end{array}$ & Motives & $\begin{array}{l}\text { Unique } \\
\text { dimensions } \\
\text { for critical } \\
\text { appraisal }\end{array}$ \\
\hline Academic & Academic & Academic & Academic & $\begin{array}{l}\text { Other } \\
\text { academic }\end{array}$ & $\begin{array}{l}\text { Fulfill } \\
\text { scientific } \\
\text { curiosity }\end{array}$ & Originality \\
\hline $\begin{array}{l}\text { Unilateral } \\
\text { Passive } \\
\text { Stakeholder }\end{array}$ & $\begin{array}{l}\text { Stakeholder } \\
\text { of one voice }\end{array}$ & Academic & Academic & Stakeholder & $\begin{array}{l}\text { Supply } \\
\text { information }\end{array}$ & $\begin{array}{l}\text { Model } \\
\text { performance }\end{array}$ \\
\hline $\begin{array}{l}\text { Unilateral } \\
\text { Active } \\
\text { Stakeholder }\end{array}$ & $\begin{array}{l}\text { Stakeholder } \\
\text { of one voice }\end{array}$ & $\begin{array}{l}\text { Academic } \\
\text { (and } \\
\text { Stakehold } \\
\text { ers) }\end{array}$ & Stakeholder & Stakeholder & $\begin{array}{l}\text { Deploy the } \\
\text { model for } \\
\text { routine use }\end{array}$ & $\begin{array}{l}\text { Model } \\
\text { usability }\end{array}$ \\
\hline $\begin{array}{l}\text { Multilateral } \\
\text { Stakeholder } \\
\text { S }\end{array}$ & $\begin{array}{l}\text { Stakeholder } \\
\text { s of multiple } \\
\text { voices }\end{array}$ & $\begin{array}{l}\text { Academic } \\
\text { and } \\
\text { stakeholde } \\
\text { rs }\end{array}$ & Stakeholders & Stakeholders & $\begin{array}{l}\text { Discipline } \\
\text { dialog and } \\
\text { stimulate } \\
\text { change }\end{array}$ & $\begin{array}{l}\text { Research } \\
\text { legitimacy } \\
\text { and } \\
\text { knowledge } \\
\text { accessibility }\end{array}$ \\
\hline
\end{tabular}

One example study that could illustrate this research orientation is Gao and Chan (2013), which was concerned with the size distribution of hospitals and its contributing factors. The authors built an agentbased model to simulate patients' behaviors of choosing hospitals, and the hospitals' response to demand change. Hospitals' size was obtained from publicly available data set, and patient visit data was drawn from a theoretical distribution. Patient and hospital interaction was based on theoretical assumptions with no external stakeholder input. There was no empirical base for many of its parameters, and therefore a sensitivity analysis was performed. To appraise this study, one would examine, for example, whether the assumptions on patient behaviors make sense given the innovative use of public data in this study. For instance, because patient preference data was not available but hospital size data was, the authors assumed that patients would choose larger size hospitals over small ones if everything else is equal.

Another example is Liu and $\mathrm{Wu}$ (2014), an agent-based model to study Accountable Care Organization (ACO) under the shared saving payment model for congestive heart failure patients. This study possesses academic value rather than real-world implications because, in reality, a shared saving program is unlikely to only consider one type of patient, but other researchers could model other chronic conditions based upon this study. This study assumed a formula for the attitude of provider agents, which was a weighted sum of the provider's expectation to financial return and expectation to health outcomes. There was no empirical evidence to support this formula, nor the different weights tested in the simulation. However, the study provides direction for future research to collect attitudinal data to verify or enhance the model. When 
appraising this study, one should acknowledge the value of originality because this is the first study applying dynamic simulation into the study of Accountable Care Organizations, which are a critical component of the U.S. healthcare reform.

\subsection{The orientation to Unilateral Passive Stakeholder}

This orientation underlines the informational value of research for decision making. The research question is usually raised by the finance, policy or operation stakeholders, such as officer of a public health department or director of a hospital, for whom researchers collect and analyze data concerning some realworld acute problems. The term "unilateral" here does not necessarily mean a single person, but rather, a group who sees the problem from a particular lens of perspective. In other words, a group with one voice. The term "passive" described the typical isolation between model developer and the knowledge user. The decision makers usually do not participate in the development and execution of the model. Among all research orientations, this orientation seems to be often adopted. In particular, this is seen in governmental contracts in which the government requests for a study, and the researcher receives money to collect data and to develop a model, with a final report back to the government. Research conducted with this orientation is mostly applied or problem-oriented and its aim is to produce information for the needs of governance and administration. The critical appraisal of these studies is conceptually similar to the appraisal of statistical prediction model in healthcare, covering domains such as source of data, participants (subjects), outcome, sample size, missing data, model assumptions and methods, performance, evaluation, results and interpretation (Moons, et al. 2014). Not every study with this orientation presents findings that can be immediately acted upon. In some studies the conclusion is that more research would be needed in order to have a potential implementation. Even when the research presents actionable findings, it could still be turned down by external factors such as bureaucracy (Greenhalgh, Howick and Maskrey 2014).

One example study that is categorized within this research orientation was carried out by Day and colleagues (Day, et al. 2013)(Day, et al. 2014), who answered the U.S. Veterans Health Administration's (VA) request for a research proposal (U.S. Department of Veterans Affairs 2012). They created a hybrid agent-based/discrete-event simulation of a diabetic retinopathy clinic, where they evaluated the effect of implementation of biannual screening of patients with no or background DR on the prevalence of blindness. The result from this study was reported back to the VA to aid decision making on their diabetes and vision care protocol. The critical appraisal of this study could find that, for example, the agent characteristics in its agent-based model is likely to be reliable because empirically fitted probability functions were used instead of hypothetical distributions. However, the reliability of the overall model is unknown due to minimum involvement of clinical staff in validating the conceptual model and the operation model. No information on whether the study findings have been acted upon by the VA could be identified by an Internet search or contact with the authors.

Another study with the same research orientation built an agent-based model to redesign the points of access to a Chilean hospital (Zambrano, et al. 2016). It is categorized within a Unilateral Passive Stakeholder because the stakeholder had one simple goal, to reduce congestion in pedestrian traffic, and they themselves did not run the computer program of the model. To critically appraise this study, one might find insufficient details on the conceptual framework and the input data. However, as recognized by the author, the model output was validated by stakeholder and compared to a similar nearby hospital. Different from the orientation to academic, this orientation should not be evaluated heavily on originality. Pedestrian traffic management is a classical application area of simulation. Here, the focus should be the re-use of a mature technique for a real world problem, which was achieved by the study.

\subsection{The Orientation to Unilateral Active Stakeholder}

This orientation differs from the orientation to passive stakeholders in the sense that the stakeholder not only utilizes the information generated from the model, but also uses the model more than one time (potentially routinely). In some cases, the stakeholder is involved in model development, thereby expanding the value of a model from informational to instrumental. It underlines the possibility of decision makers to 
utilize a model at their disposal to respond to the changing business or clinical environment. The critical appraisal of these models, in a narrow sense, is similar to the evaluation of software quality. The ISO/IEC 25000 standard is one of many frameworks to do so, covering factors like usability, maintainability, flexibility, reusability and portability (McCall, Richards and Walters 1977). The critical appraisal of these models in a broader sense is similar to evaluating a quality improvement project because a model in this case is essentially an intervention to aid decision and improve care. The QI-MQCS tool is one of many frameworks for such assessment, covering items outside the "inner quality" of a software model itself, such as adherence, health outcomes, organizational readiness, penetration, etc. (Hempel, et al. 2015).

An example with this orientation is the Scenario Generator $(\mathrm{S}: \mathrm{G})$, a simulation tool developed between the U.K. National Health Service and SIMUL8 Corporation to support strategic planning in primary care trusts (SIMUL8 Corporation 2013). One S:G model for stroke care improvement has now been used by a number of primary care trusts across England and amended to reflect local contexts and concerns (Cordeaux, Hughes and Elder 2011). The critical appraisal of $S: G$ has been conducted by a team a researchers (Brailsford, Bolt, et al. 2013) interviewing 28 primary care trusts who had been engaged in some way with the initiative. This study combined the narrower and broader angles of critical appraisal mentioned above, and interested readers are referred to it for a summary of barriers and facilitators to the successful use of this software. One of the particularly interesting findings in this study was the wide variety of individuals on whose computer the software ended up. In some instances it may have been the "obvious" person, but this was not necessarily for the best. The study suggested that it was down to particular individuals to take on the role of champion within their organization and really drive the use of the tool in a sustained manner.

Another example is an agent-based model developed for a Spanish hospital emergency department (Liu, et al. 2017). This is a very comprehensive model that if it was oriented to a passive stakeholder, it most quality points. However, because it was oriented to an active stakeholder (for the routine use of emergency department manager), it fell short on usability and was not deployed as intended.

\subsection{The Orientation to Multilateral Stakeholders}

This orientation underlines the importance of participation from a diverse group of stakeholders. "Simulation in healthcare can benefit from stakeholder participation as it makes possible to share multiple views and tacit knowledge from different parts of the system." (Kotiadis, Tako and Vasilakis 2014). The rise of this orientation borrows momentum from two broader developments, one is technology focused and the other is community focused. First, more researchers and practitioners are realizing that a pluralistic orientation that considers a multiplicity of research questions and perspectives would contribute to making studies not only rigorous, but also relevant to clinical practice, and help technology-enabled systems have a better chance of actually improving patient care (Kaplan 2001). Second is the popularity of communitybased participatory research (Cornwall and Jewkes 1995) in healthcare, a collaborative approach to research that equitably involves all partners in the research process and recognizes the unique strengths that each brings to improve community health (Minkler and Wallerstein 2008).

Built upon these development, this research orientation has become mature in recent years, as exemplified by the paper on "facilitated modeling" (Franco and Montibeller 2010) and the PartiSim group ("participative simulation") formed by several British universities (www.partisim.org). This orientation recognizes that real-world problems are socially constructed by conflicting perspectives. The goal of the research is not necessary to provide optimal solution based on a precise model, but to help the stakeholders in learning more about their problem and in gaining confidence for the way forward. Thus the model (and the result from the model) has typically less important role, as it is the support the decision making process (Franco and Montibeller 2010). As Epstein famously put it, model is to "discipline the dialog" (Epstein 2008). It is often found that the process of building the model together is as illuminating as the end result (Cordeaux, Hughes and Elder 2011) (Lane 1992). After the model is developed, stakeholders can arrange discussion in a game-like environment enabled by the simulation model, which provides a more engaging, low-risk learning lab with rapid feedback. It can strengthen stakeholders' mutual understanding and coalition for action (Mills 2014). 
How to critically appraise studies with this orientation is a challenging task. Progress in recent years has produced more holistic approaches. The International Development Research Centre's "Research Quality Plus" $(\mathrm{RQ}+)$ is one of such approaches, which argues that scientific merit is a necessary but insufficient condition for judging research quality, and also acknowledges that the determination of research effectiveness is not solely in the hands of the researchers. Assessment must also take into account whether research is perceived as salient and legitimate in the eyes of multiple stakeholders and potential users (Ofir, et al. 2016). The RQ+ Assessment Instrument contains detailed instructions for interested readers to use. Briefly, it concerns four dimensions, each could be rated from "unacceptable" to "very good". The first dimension is research integrity, which is about the technical merit, appropriateness and rigor of the design, and execution of the research as judged by commonly accepted standards for such work. The second dimension is research legitimacy, which assesses the extent to which research results have been produced by a process that took account of the concerns and insights of relevant stakeholders, and was deemed procedurally fair and based on the values, concerns and perspectives of that audience. The third dimension is research importance, which refers to the perceived importance and value of the knowledge and understanding generated by the research to key intended users. The last dimension is positioning for use, which assesses the extent to which the research process has been managed and the research products prepared in such a way that the probability of use and influence is enhanced (International Development Research Centre 2017). The RQ+ approach is likely to be more useful for assessing studies on a larger societal scale. For smaller studies, interested readers are also referred to the extensive literature on assessing the quality of qualitative research in general (Seale 1999) (National Institute for Health and Care Excellence 2012) and the quality of mixed-methodology case studies, implementation studies and action research in particular (Greenhalgh, Robert, et al. 2005) to choose the appropriate questions to ask in their appraisal.

One example study that could be categorized into this research orientation is a study to improve the operation of a Dutch hospital emergency department (Rosmulder and Luitse 2011), in which the researcher built a discrete-event simulation model with its medical director. The model was not precise (enough) at that point, but provided sufficient visual details on the behaviors of the department. This first iteration supported the discussion with a team of medical and nursing staff. They together verified the model dynamics and experimented with different improvement scenarios. The model was subsequently redefined and a pilot was carried out accordingly. An interesting part of this study was that although the pilot was successful, not every physician in the department was willing to participate. So the pilot was extended to obtain consistent favorable results to persuade more participation. When appraising this study, one may find that the research question did not seem to be formulated together between the researchers and the participants. It was technology-centered rather than health-outcome-centered, concerning whether the use of computer simulation promote action taking by all the stakeholders involved in the action research. This is not to delegitimize the research question, but it may provide an angle for readers to think about why there was unwillingness to participate from some physicians. In the end however, the authors achieved the goal of knowledge dissemination as the entire team was persuaded to adopt action.

Another example is an agent-based model serving as a game-like learning environment for multiple types of stakeholders (including legislators, insurers, obstetricians, midwives, women, etc.), to reform payment policy on cesarean delivery in the US state of Washington (Mills 2014). Similar to the previous example, this project encountered push back from physicians, and was eventually abolished (personal communication with the author), highlighting the challenges embedded in studies oriented to multiple stakeholders.

\section{DISCUSSION AND CONCLUSION}

\subsection{Research Orientation in Simulation Modelling of Complex Health Systems}

The research orientations identified from this analysis highlight the complexity of healthcare and the diversity of healthcare problems. Across all disciplines, at all levels, health care is becoming more complex (Plsek and Greenhalgh 2001), demonstrating dynamic behaviors over time (Sturmberg 2018) and calling for a shift in research paradigm. Conventional scientific quest for certainty, predictability and linear 
causality must be augmented by the study of how we can best deal with uncertainty, unpredictability and generative causality. This calls for mixed-method studies paying attention to the interconnectedness of actors from different perspectives (Greenhalgh and Papoutsi 2018). Such a way of thinking is amenable to the research orientations in healthcare simulation modeling. Analogous to the argument that a randomized controlled trial could only address a fraction of questions encounter in a complex healthcare setting, simulation models developed with the academic orientation or "unilateral passive stakeholders" orientation could only provide explanations or information for a fraction of healthcare questions ("tame" problems or structured problems). A tame problem consists of one stakeholder voice, possessed a consensual way of problem formulation, and could be possibly assessed using an "objective" criteria. On the other hand, most of the healthcare problems are "wicked" problems (or ill-structured problems) that could be viewed differently by multiple stakeholders, possess no consensual way of problem formulation and no stopping rules. It is easier to generalize findings from addressing tame problems, but harder for wicked problems since they are more unique and contextualized (Eldabi 2009) (Mingers and Rosenhead 2004). The growing popularity of the research orientation to multilateral stakeholders shows a promising trend of practitioners embracing pluralism and complexity in healthcare.

It is worth noting that there is no such a thing as the best research orientation. In many cases, the research orientation is pre-determined by who funds the research (Hakala and Ylijoki 2001) or the nature of the research question. In other cases, the consumer of the research may have strong preference or control on who would need to participate and on what the level of participation. For example, in the context of healthcare management consulting, many client leaders would prefer to distance themselves from the process in order to establish an independent and "neutral" perception on the consultancy (Lalonde and Adler 2015). Researchers could attempt to change that if they find it inappropriate for the research, but this might not be easy. When the researcher indeed has a choice, playing a facilitator role among multilateral stakeholders is promising to have bigger impact, although the evidence on its effectiveness is still scant (Franco and Montibeller 2010), not to mention that it is much harder for the researcher to master the required skills (Lalonde and Adler 2015).

Although these research orientations are characterized in mutually exclusive categories in this analysis, in reality it is a continuum without a clear cut. A research can be oriented to a major stakeholder but, for example, also involve other stakeholders to participate. They could also co-exist in a research project at the same time, or at different phases of a research project (Lalonde and Adler 2015). Some also argue that because facilitating multi-stakeholder dialogs and actions requires a different mindset than programming a simulation model in computer, it is perfectly acceptable to have different individuals carrying these two roles, given that they work closely with each other (Robinson, et al. 2014) (Rosmulder, Krabbendam, et al. 2011). This, of course, places specific challenges for critical appraisal, which is worth a separate research in its own right.

\subsection{Limitations of this study}

Most articles analyzed in this paper are from a systematic review that was conducted by the first author as a master's thesis (Chen 2018). In addition to the limitations noted in the thesis (e.g., only English keywords were used in the search), the thesis has not been submitted for peer-reviewed publication, and other methodological issues may apply. Another limitation is that we are not able to provide checklist-style tools for quality assessment. Development of such tools requires multiple rounds of consensus building and testing, which is beyond the scope of this paper. We, however, believe that we have provided sufficient discussion on the principles for the future design of these tools.

\subsection{Conclusion}

Four research orientations are identified from a framework analysis of literature in healthcare simulation modeling. From one orientation to the next, more stakeholders with more diverse opinions participate more steps in the research. In particular, the orientation to multilateral stakeholders, with its root in the new mode of knowledge production, shows an encouraging trend of practitioners embracing pluralism and complexity 
in healthcare. We argue that there is no one correct level of stakeholder engagement, one quality assessment checklist or one best way to realize value of a model. It all depends on the research orientation, which is in turn determined by the research funders, the nature of the research question and the consumer-research relationship. In some situations, implementation of a precise model is a reasonable measure of success, while in other situations a not-that-precise model could still be valuable because its disciplines dialogs and stimulates changes. Based upon this study, future research should verify the categorization of research orientations by applying it to a different set of studies, which ideally should include studies conducted in low- and middle-income countries or written in non-English languages. Future research could also base upon the principles discussed in this study to develop quality assessment tools, following rigorous methods such as the "Scoping, Evidence Review, Delphi Method, Piloting and Refining" process used in developing quality assessment tool for clinical prediction modeling studies (Wolff, et al. 2019).

\section{ACKNOWLEDGMENTS}

We thank Dr. Alan Mills and three anonymous reviewers for their constructive feedback on the paper.

\section{REFERENCES}

Barbour, R. 2008. Introducing Qualitative Research. London, UK: Sage Publications Ltd.

Boell, S., and D. Cecez-Kecmanovic. 2014. "A Hermeneutic Approach for Conducting Literature Reviews and Literature." Communciation of the Association for Information Systems 257-286.

Brailsford, S. C. 2014. "Discrete-event simulation is alive and kicking." Journal of Simulation 8 (1): 1-8. doi:10.1057/jos.2013.13.

Brailsford, S. C., T. B. Bolt, G. Bucci, T. M. Chaussalet, N.A. Connell, P. R. Harper, J. H. Klein, M. Pitt, and M Taylor. 2013. "Overcoming the barriers: a qualitative study of simulation adoption in the NHS." Journal of the Operational Research Society 64 (2): 157-168. doi:10.1057/jors.2011.130.

Brailsford, S. C., P. R. Harper, B. Patel, and M. Pitt. 2009. "An analysis of the academic literature on simulation and modelling in health care." Journal of Simulation 3: 130-140.

doi:10.1057/jos.2009.10.

Chen, J. 2018. Agent-based Modelling in Healthcare Operations: A Systematic Review of its Scope, Quality and Implementation. Oxford, United Kingdom: Master's thesis, University of Oxford. Accessed Jan 2019. https://ora.ox.ac.uk/objects/uuid:9b71bc9f-61c1-4485-93b2-0b7e17e0e62f.

Cordeaux, C., A. Hughes, and M. Elder. 2011. "Simulating the impact of change: implementing best practice in stroke care." London journal of primary care 4 (1): 33-37.

Cornwall, A., and R. Jewkes. 1995. "What is participatory research?" Social Science \& Medicine 41 (12): 1667-1676. https://www.ncbi.nlm.nih.gov/pubmed/8746866.

Day, T. E., N. Ravi, H. Xian, and A. Brugh. 2014. "Sensitivity of diabetic retinopathy associated vision loss to screening interval in an agent-based/discrete event simulation model." Computers in Biology and Medicine 47: 7-12. doi:10.1016/j.compbiomed.2014.01.007.

Day, T. E., N. Ravi, H. Xian, and A. Brugh. 2013. "An Agent-Based Modeling Template for a Cohort of Veterans with Diabetic Retinopathy." PLOS One 8 (6): e66812. doi:10.1371/journal.pone.0066812.

Eldabi, T. 2009. "Implementation Issues of Modelling Healthcare Problems: Misconceptions and Lessons." Proceedings of the Winter Simulation Conference. Austin: The Institute for Operations Research and the Management Sciences. 
Epstein, J. M. 2008. "Why Model?" Journal of Artificial Societies and Social Simulation 11 (4): 12. http://jasss.soc.surrey.ac.uk/11/4/12.html.

Fone, D., S. Hollinghurst, M. Temple, A. Round, N. Lester, A. Weightman, K. Roberts, E. Coyle, G. Bevan, and S. Palmer. 2003. "Systematic review of the use and value of computer simulation modelling in population health and health care delivery." Journal of Public Health Medicine 25 (4): $325-335$.

Franco, L. A., and G. Montibeller. 2010. "Facilitated modelling in operational research." European Journal of Operational Research 205 (3): 489-500. doi:10.1016/j.ejor.2009.09.030.

Gale, N. K., G. Heath, E. Cameron, S. Rashid, and S. Redwood. 2013. "Using the framework method for the analysis of qualitative data in multi-disciplinary health research." BMC Medical Research Methdology 13: 117. doi:10.1186/1471-2288-13-117.

Gao, B., and W. K. Chan. 2013. "Sub-Lognormal Size Distribution of hospitals - An Agent-based Approach and Empirical Study." Proceddings of the Winter Simulation Conference. Washington, DC: IEEE Press.

Gibbons, M., C. Limoges, H. Nowotny, S. Schwartzman, P. Scott, and M. Trow. 1994. The New Production of Knowledge: The Dynamics of Science and Research in Contemporary Societies. London; Thousand Oaks, Calif.: SAGE Publications.

Greenhalgh, T. 2014. How to Read a Paper: The Basics of Evidence-Based Medicine. Fifth. West Sussex: John Wiley \& Sons.

Greenhalgh, T., and C. Papoutsi. 2018. "Studying complexity in health services research: desperately seeking an overdue paradigm shift." BMC Medicine 16 (95). doi:10.1186/s12916-018-1089-4.

Greenhalgh, T., G. Robert, P. Bate, F. Macfarlane, and O. Kyriakidou. 2005. "Appendix 2: Critical Appraisal Checklist." In Diffusion of Innovations in Health Service Organisations: A systematic literature review, 234-244. Hoboken, New Jersey: Blackwell Publishing Ltd.

Greenhalgh, T., J. Howick, and N. Maskrey. 2014. "Evidence based medicine: a movement in crisis?" $B M J$ 348: g3725. doi:10.1136/bmj.g3725.

Greenhalgh, T., S. Thorne, and K. Malterud. 2018. "Time to challenge the spurious hierarchy of systematic over narrative reviews?" European Journal of Clinical Investigation 48: e12931. doi:10.1111/eci.12931.

Hakala, J., and O.-H. Ylijoki. 2001. "Research for Whom? Research Orientations in Three Academic Cultures." Organization 8 (2): 373-380. doi:10.1177\%2F1350508401082021.

Hempel, S., P. G. Shekelle, J. L. Liu, M. S. Danz, R. Foy, Y.-W. Lim, A. Motala, and L. V. Rubenstein. 2015. "Development of the Quality Improvement Minimum Quality Criteria Set (QI-MQCS): a tool for critical appraisal of quality improvement intervention publications." BMJ Quality \& Safety 24: 796-804. doi:10.1136/bmjqs-2014-003151.

Higgins, J. P. T., and S. Green. 2011. "Cochrane Handbook for Systematic Reviews of Interventions." www.handbook.cochrane.org.

International Development Research Centre. 2017. "The Research Quality Plus (RQ+) Assessment Instrument." Research Quality Plus. December. Accessed February 9, 2019. https://www.idrc.ca/sites/default/files/sp/Documents\%20EN/idrc_rq_assessment_instrument_sept ember_2017.pdf. 
Jahangirian, M., Simon J. E. T., J. Eatock, L. K. Stergioulas, and P. M. Taylor. 2015. "Causal study of low stakeholder engagement in." Journal of the Operational Research Society 66 (3): 369-379.

Kaplan, B. 2001. "Evaluating informatics applications - some alternative approaches: theory, social interactionism, and call for methodological pluralism." International Journal of Medical Informatics 64 (1): 39-56. doi:10.1016/S1386-5056(01)00184-8.

Kotiadis, K., A. A. Tako, and C. Vasilakis. 2014. "A participative and facilitative conceptual modelling framework for discrete event simulation studies in healthcare." Journal of the Operational Research Society 65 (2): 197-214. doi:10.1057/jors.2012.176.

Lalonde, C., and C. Adler. 2015. "Information asymmetry in process consultation: An empirical research on leader-client/consultant relationship in healthcare organizations." Leadership \& Organization Development Journal 36 (2): 117-211. doi:10.1108/LODJ-03-2013-0037.

Lane, D. 1992. "Modelling as learning: A consultancy methodology for enhancing learning in management teams." European Journal of Operational Research 59 (1): 64-84. doi:10.1016/0377-2217(92)90007-V.

Liu, P., and S. Wu. 2014. "An agent-based simulation model to study accountable care." Health Care Manag Sci. doi:10.1007/s10729-014-9279-x.

Liu, Z., D. Rexachs, F. Epelde, and E. Luque. 2017. "An agent-based model for quantitatively analyzing and predicting the complex behavior of emergency departments." Journal of Computational Science 11-23. doi:10.1016/j.jocs.2017.05.015.

McCall, J. A., P. K. Richards, and G. F. Walters. 1977. Factors in Software Quality. Volume I. Concepts and Definitions of Software Quality. Fort Belvoir, Virginia: Defense Technical Information Center.

Mills, A. 2014. "Cesarean Delivery Model: Meeting the challenge to reduce rates of Cesarean delivery." AnyLogic Conference 2014. November 13. Accessed January 5, 2018. https://www.anylogic.com/upload/conference/2014/Alan_MillsAnyLogicPresentation_v3_Draft1_AnyLogic.pdf.

Minkler, M., and N. Wallerstein. 2008. Community-Based Participatory Research for Health: Fro Process to Outcomes. 2nd. West Sussex: John Wiley \& Sons.

Moons, K. G. M., J. A. H. de Groot, W. Bouwmeester, Y. Vergouwe, S. Mallett, D. G. Altman, J. B. Reitsma, and G. S. Collins. 2014. "Critical Appraisal and Data Extraction for Systematic Reviews of Prediction Modelling Studies: The CHARMS Checklist." PLOS Medicine 11 (10): e1001744. doi:10.1371/journal.pmed.1001744.

Wolff R. F., K.G. Moons, R.D. Riley, P. F. Whiting, M. Westwood, G. S. Collins, J. B. Reitsma, J. Kleijnen, S. Mallett. "PROBAST: A Tool to Assess the Risk of Bias and Applicability of Prediction Model Studies". Annals of Intern Medicine;170:51-58. doi: 10.7326/M18-1376

National Institute for Health and Care Excellence. 2012. Appendix H Quality appraisal checklistqualitative studies. Accessed December 23, 2018.

https://www.nice.org.uk/process/pmg4/chapter/appendix-h-quality-appraisal-checklistqualitative-studies.

Nature editors. 2018. "The best research is produced when researchers and communities work together." Nature 562 (7). doi:10.1038/d41586-018-06855-7.

Ofir, Z., T. Schwandt, C. Duggan, and R. McLean. 2016. Research Quality Plus. Ottawa: International Development Research Centre, Canada. 
Plsek, P. E., and T. Greenhalgh. 2001. "Complexity science: The challenge of complexity in health care." BMJ 625-628.

Robinson, S., C. Worthington, N. Burgess, and Z. J. Radnor. 2014. "Facilitated modelling with discreteevent simulation: Reality or myth?" European Journal of Operational Research 234 (1): 231-240. doi:10.1016/j.ejor.2012.12.024.

Rosmulder, R. W., and J. J. Krabbendam: A. Kerkhoff: C. M. Houser: J. S. K. Luitse. 2011. "Computer Simulation Within Action Research: A Promising Combination for Improving Healthcare Delivery?" Systemic practice and action research 24 (5): 397-412. doi:10.1007/s11213-0119196-6.

Seale, C.. 1999. The Quality of Qualitative Research. London: SAGE Publications Ltd.

Siebers, P. O., C. M. Macal, J. Garnett, D. Buxton, and M. Pidd. 2010. "Discrete-event simulation is dead, long live agent-based simulation!" ournal of Simulation 4 (3): 204-210.

SIMUL8 Corporation. 2013. What is Scenario Generator? Accessed December 16, 2018. http://www.scenario-generator.com/about.

Sturmberg, J. P. 2018. "Embracing complexity in health and health care-Translating a way of thinking into a way of acting." Journal of Evaluation in Clinical Practice 24: 598-599. doi:10.1111/jep.12935.

U.S. Department of Veterans Affairs. 2012. PPO 11-167: Simulation Modeling for Implementation Analysis. Accessed December 16, 2018. https://www.hsrd.research.va.gov/research/abstracts.cfm?Project_ID=2141701671.

Zambrano, F., P. Concha, F. Ramis, L. Neriz, M. Bull, P. Veloz, and J. Carvajal. 2016. "Iimproving Patient Access to a Public Hospital Comlex Using Agent Simulation." Proceeding of the Winter Simulation Conference. Washington DC: IEEE.

\section{AUTHOR BIOGRAPHIES}

JUNQIAO CHEN is an Associate Director of Clinical Informatics at Evolent Health. He holds a MSc in Evidence-based Health Care from University of Oxford and a Master of Management in Clinical Informatics from Duke University. He is pursuing a $\mathrm{PhD}$ in Complexity Sciences jointly offered by the University of Lisbon and ISCTE University Institute of Lisbon. His email is qchen@evolenthealth.com.

MONICA DUARTE OLIVEIRA is an Associate Professor of Decision Sciences at the Department of Engineering and Management of Instituto Superior Técnico (IST) and a researcher at the Centre for Management Studies of IST. Her research interests include the development of management science models to assist policy and decision makers in health and clinical settings, with a special interest in multicriteria value modelling using participatory processes. She holds a degree in Economics by the University of Porto and a MSc and PhD in Operational Research by the London School of Economics and Political Science. Her email address is monica.oliveira@tecnico.ulisboa.pt.

ALEXANDRA FERMANDES is a tenured professor in the Marketing, Operations Management and Global Management department at ISCTE (Portugal). She is director of BSc in Management and MSc in Art Markets. She has published articles in international and national scientific journals and several academic books. She holds BSc in Corporate Finance, a MSc in Human Resources Politics and Management and a $\mathrm{PhD}$ in Management. Her email address is alexandra.fernandes@iscte-iul.pt.

DAVID CHUN is a clinical informatics intern at Evolent Health. He holds a BS in Health Administration and Policy with a concentration in Health Informatics from George Mason University. His email address is davidjaychun@gmail.com. 